\title{
Using Balanced Scorecards to Manage IT Strategies in Public Organizations: The Case of Jeddah Municipality
}

\author{
Arwa Yousuf Al-Aama ${ }^{1}$ \\ ${ }^{1}$ Department of Computer Science, King Abdulaziz University, Jeddah, Saudi Arabia \\ Correspondence: Arwa Yousuf Al-Aama, Department of Computer Science, King Abdulaziz University, P.O. \\ Box 16735, Jeddah 21474, Saudi Arabia. Tel: 966-503-378-432. E-mail: aalaama@gmail.com
}

Received: March 26, 2013

Accepted: April 22, 2012 Online Published: April 28, 2013

doi:10.5539/emr.v2n1p111

URL: http://dx.doi.org/10.5539/emr.v2n1p111

\begin{abstract}
The Balanced Scorecard (BSC), used for performance measurement and strategy management, is composed of four perspectives linked by cause and effect relations in the following order: Learning and Growth, Internal Processes, Customers, and Financial, with the financial perspective being the final outcome. This paper describes how the IT Department at the Jeddah Municipality adopted the BSC to match its strategic objectives as a nonprofit function of a public service organization, placing its financial perspective as an input and its Customer perspective as the final outcome. This is in line with the fact that the IT Department uses budgets allocated by the government and is customer-centric, not profit-centric. The concept of altering the BSC by placing the Customer perspective at the top, which is proposed in this paper, can be used by other public service organizations which aim to be customer-centric. The paper also demonstrates how the Jeddah Municipality IT BSC guides the Municipality IT strategy, management, and budget planning and provides two tools which complement the IT BSC which are the Project and Strategic Objectives Matrix and the Project and Budget Planning Matrix.
\end{abstract}

Keywords: balanced scorecards, information technology strategy, strategy management, performance management, technology management, Jeddah, Saudi Arabia, municipality

\section{Introduction}

Government organizations around the world strive to improve their performance and achieve their goals which typically imply providing people with better services and improved quality of life. Developing strategies with clear visions, missions and objectives has become the norm for many of these organizations. Several strategic frameworks exist to guide organizations in their strategy management and delivery. Models also exist to assist organizations in measuring performance. These models normally measure performance based on financial results of the organizations, which is normally at the core of businesses. Examples of these models include the popular Return-on-Investment or ROI, which is used to calculate the benefit or return of an investment in a project or projects compared to the cost that was spent on it using financial terms. They also include other methods such as the Payback Period, known as PB, which measures how long an organization would have to wait until it is paid back what it invested in a project (Simon, 2003). Clearly, that model also depends on financial figures. Market Share, Return-on-Equity (ROE), popular Profit and Loss Statements, Cash Flow Statements, and many others also focus on financial outcomes. These models, thus, are not truly suitable for government organizations in which performance is normally measured by other factors such as improving citizen quality of life and stakeholder satisfaction with their services, as opposed to financial measures.

This paper describes how the Jeddah Municipality (JM) IT Department in Saudi Arabia uses the Balanced Scorecard (BSC) as a model for its strategy, by customizing it to match its needs and priorities. JM changed the order of the four perspectives in a standard BSC, which are namely: Learning and Growth, Internal Processes, Customers and Financial perspectives, and are normally linked by cause and effect relations from bottom to top in that order. Unlike the standard BSC, where the Financial perspective is placed at the top, JM placed the Customer perspective at the top of the BSC and the Financial perspective at the bottom. This is in line with how $\mathrm{JM}$ operates, where budgets are injected into the JM operation and satisfying clients is the most important strategic outcome, forcing JM to put the Customer perspective at the top, which is indicative of it being the most important objective, or outcome, for JM. 
The paper later describes how the JM IT Department, which currently serves 62 branches across the JM region, spread over about 5500 square kilometers, has developed its BSC to be aligned with the main JM BSC, including the new order of its four quadrants. The paper addresses each of the quadrants, its stated strategic objectives, and the measures, or Key Performance Indicators (KPIs), for each objective. The JM IT BSC, thus, can serve as a model for IT Strategies for similar organizations which are targeted for public service, and in which budgets are allocated from the government and not gained through its operation.

\section{Literature Review}

\subsection{The Balanced Scorecard}

The Balanced Scorecard, introduced by Kaplan and Norton in the early 1990s, is a framework for organizations to use to translate their missions and strategies into a comprehensive set of performance measures that enable them to assess how much of their strategies they have achieved and how they can move towards their goals. These measures are normally known as key performance indicators. The BSC helps organizations focus on what they want to achieve (their goals) as opposed to how much are they making (their profits). The BSC was originally introduced to improve corporate performance measurement by balancing lagging metrics of financial performance with nonfinancial metrics that drive future performance, thus extending its use from a performance evaluation tool to a strategy management tool (Kaplan and Norton, 1996A). According to Kaplan and Norton in Mark (2012), the BSC was introduced because exclusive reliance on financial measures could not drive sustainable value creation, as financial measures are lag indicators that report on the outcomes from past actions; and exclusive reliance on these measures encourages behavior that sacrifices long-term value creation for short-term performance. The BSC includes measures for intangible assets, such as "customer relationships, innovative products and services, high-quality and responsive operating processes, skills and knowledge of the workforce, the information technology that supports the workforce and links the firm to its customers and suppliers, and the organizational climate that encourages innovation, problem solving, and improvement" (Mark, 2012). These are measures which are derived from an organization's mission and strategy and focus on future results (Kaplan and Norton, 1996A).

The original BSC is organized into four quadrants each representing a different perspective of the organization. These are: Financial, Customer, Internal Processes, and Learning and Growth perspectives. The Financial perspective includes items such as profitability, growth and shareholder value. The Customer perspective focuses on items related to customer feedback and opinion of products and services. The Internal Processes Perspective focuses on the efficiency of internal processes and procedures. Finally, the Learning and Growth perspective focuses on the ability of an organization to learn and grow; this includes the organization's human and technical assets. Each of these quadrants has its own evaluation metrics.

The BSC was originally created to measure performance of for-profit businesses and thus the overall performance of an organization was evaluated by its financial results. This meant that the final major outcome was focused on measurements found in the financial perspective. As the BSC links both financial and intangible assets of an organization in value-creating activities, it is represented by a diagram known as a Strategy Map which contains four rectangles placed on top of each other, each representing one of the four perspectives, with the following order from bottom to top: Learning and Growth, Internal Processes, Customer, and Finance, as represented in Figure 1. The Strategy Map also places objectives for each perspective into each rectangle, where the strategy's critical elements and the linkage between them are organized on a cause-and-effect relationship base. For example, learning and growth leads to the improvement of the internal business process, which in turn leads to customer satisfaction improvement and finally affects the financial improvement of the company (Kaplan and Norton, 2001A).

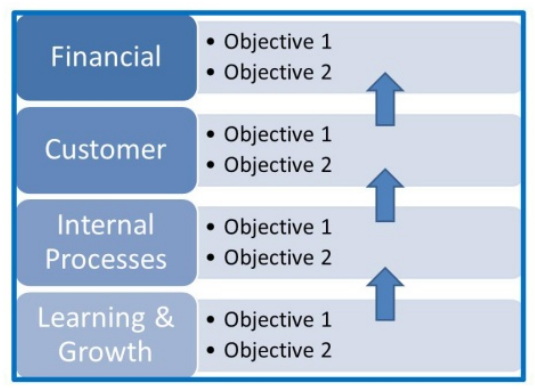

Figure 1. The quadrants of a standard BSC strategy map (Derived from Kaplan and Norton, 1992) 


\subsection{The BSC for Strategy Management}

The BSC is a management assessment system that has evolved from its initial purpose as a performance measurement tool to become an integrated part of strategic planning and management. The BSC does so by introducing a few main processes for managers. These processes are: translating the organization vision, communicating the strategy across the organization and linking it to departmental and individual objectives, business planning, and feedback and learning (Kaplan \& Norton, 1996b).

Connecting BSC concepts to a strategic plan is the key to the success of a BSC system (Susan, 2011). Furthermore, strategy maps illustrate the processes for transforming intangible assets into tangible customer and financial outcomes, providing executives with a framework for describing and managing strategies (Kaplan and Norton, 2000). They also allow managers to monitor progress of the strategy implementation and identify means for improvement, and enable them to align budgets with strategies.

The BSC, as a strategy management system, places the vision of an organization at the core of the implementation plan. It shows employees in a snapshot view where they are and where they should go. It motivates workers to participate in the delivery of the goals and objective achievement. It also guides upper management to monitor progress and appropriate allocation of resources that help deliver the final outcomes which the organization strategy has identified. According to Kaplan and Norton, as found in Mark 2012, the steps to do so include: translating a clear strategy into a strategy map and BSC, identifying and funding strategic initiatives that drive performance improvement, aligning organizational units and employees to the strategy, linking operational improvement programs and local dashboards to strategic priorities, conducting strategy review and updating meetings throughout the year, and instituting a small Office of Strategy Management to oversee these strategy implementation processes (Mark, 2012).

The BSC supplements traditional financial measures with criteria that measures performance in three additional operational perspectives. According to Kaplan and Norton (1992), these perspectives are: customers (How do customers see us?), internal processes (What must we excel at), and learning and growth of the organization (Can we continue to improve and create value?), in addition to the Financial perspective (How do shareholders see us?). Furthermore, by allowing senior managers to view the complete picture of a strategy using the BSC, they are able to see whether the success in one area has positively, or negatively, affected the other, as it contains the cause-and-effect links, thus, supporting strategists and managers in their efforts to improve overall performance by changing or adjusting their efforts in a particular area.

Since its introduction in 1992, at least $60 \%$ of Fortune 1000 organizations use a BSC system (Niven, 2008). Evidence of positive performance effectiveness of BSCs in organizations exists in the literature. For example, De Geuser et al. (2009) report positive impacts which are primarily based on better and continuous strategizing and greater alignment of organizational processes, competencies, structures and services. Simon (2005) reports improved departmental planning and evaluation. In addition, Gomes et al. (2013) report improved investment effectiveness when BSCs are used in planning.

Strategy maps, in turn, have been found to provide several benefits to organizations when used as part of strategy management, including improving performance evaluation decisions (Banker et. al, 2011).

\subsection{Balanced Scorecard Framework for Public Sector}

A few years after its introduction to the business world, Kaplan and Norton realized that public-sector and nonprofit organizations can make important use of the BSC, as these organizations cannot describe, communicate, or implement their strategies using financial metrics alone. They suggested a main change when moving the BSC framework from the for-profit to the nonprofit sectors, which is to elevate the Customer (or Stakeholder) Perspective, which now represents citizens and constituents, to the top perspective of strategy maps and scorecards, over the Financial perspective, as shown in Figure 2. This is because these organizations measure their performance not by financial profits but by their effects on citizens and the public. This was done, according to Kaplan and Norton (2001), because many public organizations had difficulties with the original architecture of the BSC which places the Financial perspectives at the forefront, followed by the Customer, Internal Process and Innovation and Learning (or Learning and Growth) dimensions.

Anthoula and Alexandros (2011) also proposed using the same variation to be applied by government organizations, but in addition, they also proposed for each of the four perspectives of the model, a three-level sub-system which contains one strategic goal, three to four objectives and up to five performance drivers for every objective. 


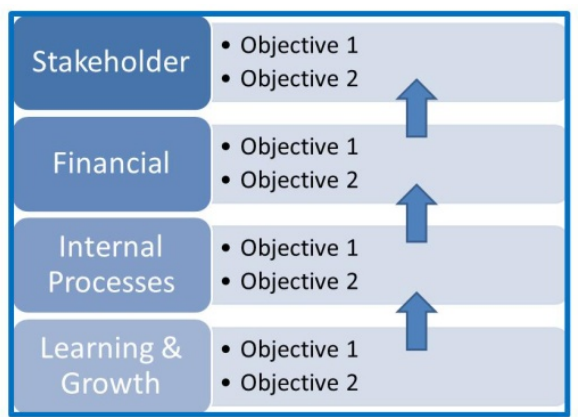

Figure 2. Balanced scorecard modified for government organizations

(Derived from Anthoula and Alexandros (2011))

Anthoula and Alexandros (2011) also list other examples of the use of the same new BSC model, where the Citizen perspective is placed at the top of the BSC, as opposed to the Financial perspective. These examples include the City of Charlotte North Carolina, the Department of Defense in the U.S., and the Canadian National Defense, to name a few. The other perspectives were left in place.

Kaplan and Norton also emphasize that the BSC is just a sample and should be modified according to determining factors of a company or industry, according to the subject which a business acts in, and based on selected strategy. Accordingly, the numbers of perspectives could be increased or one perspective could be replaced by another. In addition, the BSC concept could be applied for assessing, evaluating and conducting activities in specific functional areas of a business, even at the level of a single project (Niven, 2003; Keyhanifar, 2012).

\section{The Jeddah Municipality Balanced Scorecard}

Although the new modified BSC Model is better suited for a public organization than the original BSC, it still implies that financial outcomes are one of the higher perspectives in importance. This makes it not suitable for certain public organizations where the Financial perspective is an input and not an outcome, such as the case of Saudi governmental organizations in general and Saudi Municipalities in particular. In these organizations, the government invests budgets to achieve citizen satisfaction. Thus both BSC models will not be well suited for their use, as making financial profits is not their aim, but satisfying its customers' needs is. Customers in this case are most likely the citizens and inhabitants in the region where that body operates, or what can be referred to as 'Stakeholders'.

This, lead the Jeddah Municipality to change the order of the BSC perspectives to enable the Customer (or stakeholder) perspective to be the final important outcome/ perspective, as opposed to the traditional BSC where the Financial quadrant is placed at the top of the BSC. It also placed the financial quadrant at the very bottom of the strategy map, showing that money is an income in the map and not an outcome, as shown in Figure 3. Money, in this case, is one of the drivers that aide in achieving the JM goals and its final required outcome is satisfying stakeholders.

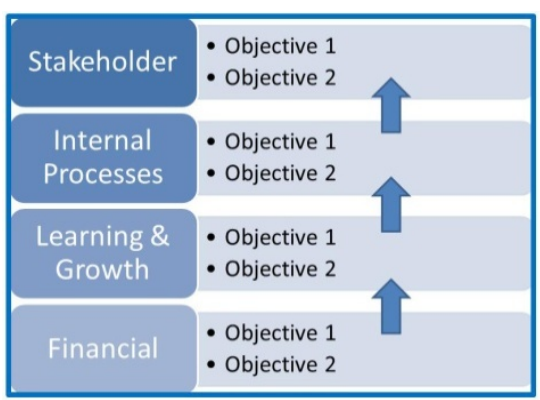

Figure 3. Balanced scorecard modified by JM (Derived from Jeddah Municipality, 2012)

The annual JM budget is estimated to be around 480 million US Dollars. The budget is received from the government to enable JM to carry out its planned projects and to cover its spending. The Saudi government does not charge citizens with taxes. 
JM uses this new BSC model for its overall performance evaluation and strategy management. Furthermore, it uses separate balance scorecards for each of its departments which are cascaded down from the main JM BSC. The different departments BSCs, however, share some common objectives and measures. These are mainly in the Learning and Growth perspective, and are placed as is in the different departmental scorecards.

\section{Strategy Management and the Jeddah Municipality IT Department BSC}

The JM IT Department, like all other JM Departments, developed its own BSC with aide from the Strategy and Performance Measurement Department at JM. The JM IT BSC was derived from the JM main BSC in order to assure the alignment of the IT strategy with the main JM overall strategy. The weights and overall design are cascaded down from the overall JM Strategy Map but edited to match the strategic goals of the IT Department.

At JM, the IT department was mainly established to serve two main communities: employees and other departments and external JM stakeholders, such as citizens, businesses, and investors. Furthermore, the IT department uses budgets provided by the government and is not targeted to generate income. With these two items in mind, the Strategy and Performance Department at JM held a series of workshops with IT Department heads, where the 5-year strategy (2009 -2014) was developed. The vision and mission were identified first. Next, the strategic objectives and department values were identified. A SWOT analysis was then conducted and the strategy was mapped out, along with the BSC and Strategy Map.

According to (Jeddah Municipality, 2012), the IT Strategy Map was based on the following assessment elements:

- JM leadership vision and directions

- Assessment of current IT strategy execution status

- Business requirements as expressed in interviews with JM management

- Assessment of current IT assets, process, and people

- Revision of the current set of active and proposed IT projects (various execution stages)

The following guidelines in developing the IT Strategy were used:

- Getting more focus on leveraging the efforts done in the previous 2 years (2007-2008), and having them felt by end users.

- Limiting the number of high level technology objectives to less than 15 objectives to attain required focus and to achieve required impact on JM business.

- Detail some of the objectives in specialized technology areas strategies such as E-Government Strategy, and E-Participation and E-Communication Strategy.

- Focusing on the areas where slower progress was noticed, or where a noticeable impact on users can be achieved.

At JM, departments which are identified as service providers, such as the IT Department, use a $50 \%$ weight for their Customer perspective quadrant. Furthermore, L and G quadrants are standardized throughout JM, where all these quadrants are given a $10 \%$ weight and all contain the same Objectives and KPIs.

Based on all of the above, the JM IT BSC, as shown in Figure 4, was constructed of the four traditional BSC quadrants. However, from bottom to top these quadrants were placed in the following order: Financial, Learning and Growth, Internal Processes and, finally at the top, the Customer perspective quadrant. Each quadrant was devised to contain a group of strategic objectives, where each objective has one or more KPI to measure progress on that objective.

Following are the list of objectives and corresponding KPIs, which are used as measuring tools. 


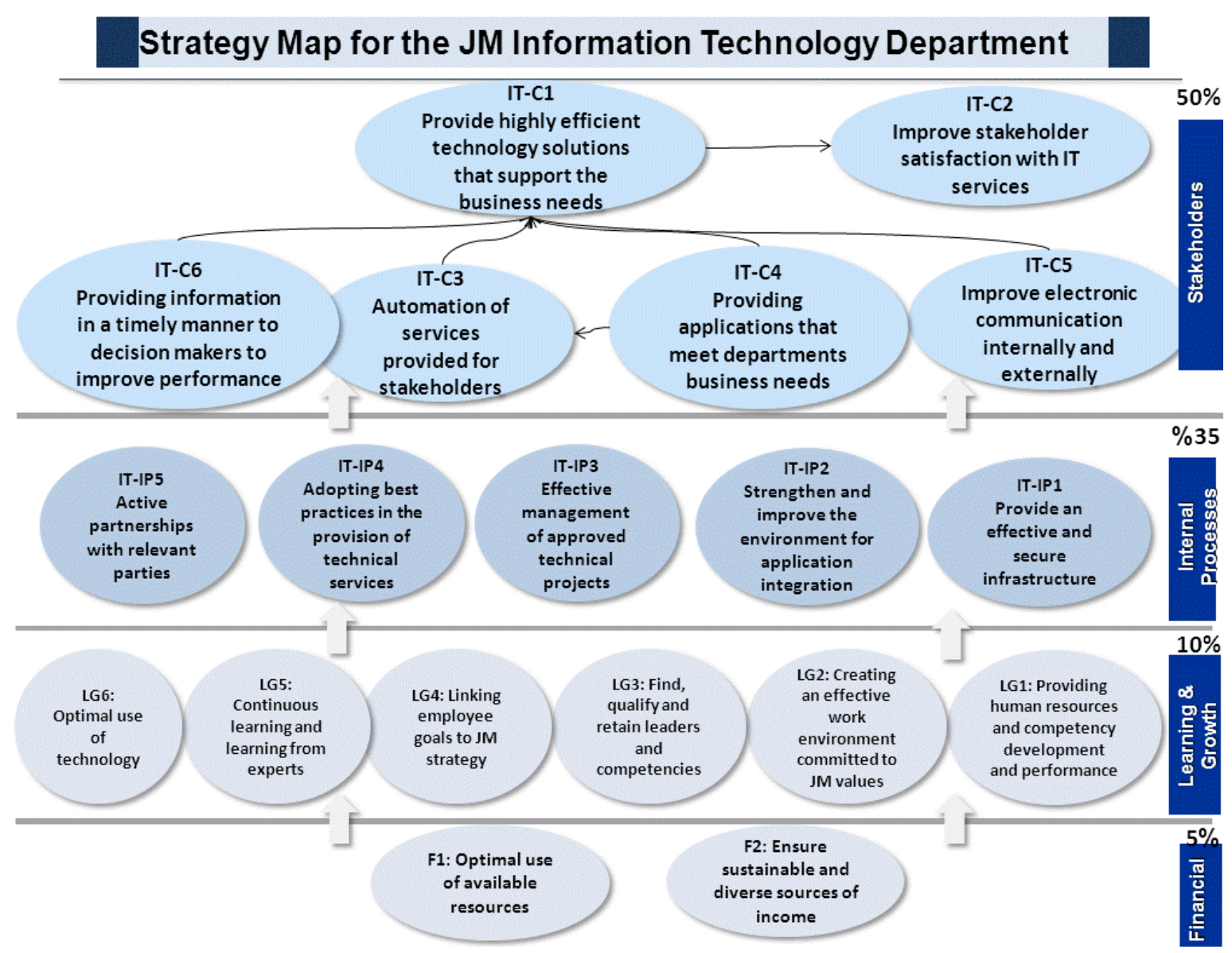

Figure 4. The JM IT BSC strategy map (Jeddah Municipality, 2012)

The following sections define the JM Strategic objectives. The names of the objectives where chosen based on the perspectives they represent. All 'Customer' perspective measures start with the letter ' $\mathrm{C}$ ', all 'Internal Process' perspective measures start with the letters 'IP', all 'Learning and Growth' perspective measures start with the letters 'LG', and all 'Financial' perspective measures start with the letter ' $F$ '. The ' $M$ ' in the second section of the names is an abbreviation for the word 'Measure'. In addition, the initial IT in all objectives represent the fact that they belong to the IT department BSC at the Jeddah Municipality, to enable the organization to tag the ownership of the objective in the event an objective is discussed out of the scope of the IT Department.

\section{Customer/Stakeholder perspective objectives and KPIs}

- IT-C1: Provide highly efficient technology solutions that support the business needs :

1. C1M1: Indicator of the readiness of the technical environment

2. C1M2: Percentage of resolved complaints and incidents

3. C1M3: Percentage of departments that have been qualified for electronic archiving

- IT-C2: Improve stakeholder satisfaction with IT services

4. C2M1: Staff satisfaction with information technology management services indicator

5. C2M2: Stakeholder satisfaction with complaints and incident resolution indicator

- IT-C3: Automation of services provided for stakeholders

6. C3M1- The percentage of electronic services that are automated

7. C3M2- The number of enabled electronic service delivery channels

8. C3M3- The number of services that are shared with the national e-Government integration hub

- IT-C4: Providing applications that meet departments business needs

9. C4M1-Completion rate of application automation plan 
- IT-C5: Improve electronic communication internally and externally

10. C5M1- The number of JM website hits

11. C5M2- The number of posts in the JM electronic sites and web 2.0 channels

12. C5M3- Percentage of employees using the employee portal

13. C5M4- The number of visits to the JM Knowledge Center

- IT-C6: Providing information in a timely manner to decision makers to improve performance

14. C6M1- The number of application databases that are added to the business intelligence system

15. C6M2- The average number of times intelligent reports are used

Internal Process perspective objectives and KPIs

- IT-IP1: Provide an effective and secure infrastructure

1. IP1M1- Readiness Indicator of the JM branches data centers

- IT-IP2: Strengthen and improve the environment for application integration

2. IP2M1- Systems Integration indicator

- IT-IP3: Effective management of approved technical projects

3. IP3M1- Percentage of projects' completion

4. IP3M2- Quality of project implementation indicator

- IT-IP4: Adopting best practices in the provision of technical services

5. IP4M1- Number of re-engineered applications

6. IP4M2- Number of international standards adhered to in the IT operation

7. IP4M3- Number of awards received

- IT-IP5: Active partnerships with relevant parties

8. IP5M1- The number of late replies to internal correspondence ( $>1$ month)

Learning and Growth perspective objectives and KPIs

- IT-LG1: Providing human resources and competency development and performance

1. LG1M1- Average number of training days per employee

2. LG1M2- Percentage of employees who became IT certified

3. LG1M2- Percentage of those who completed self-development plans

- IT-LG2: Creating an effective work environment committed to JM values

4. LG2M1- Staff satisfaction index using (Gallup)

5. LG2M2- Violation rate per employee

- IT-LG3: Find, qualify and retain leaders and competencies

6. LG3M1- Job rotation average

7. LG3M2- 360 degrees skill level

8. LG3M3- Number of Staff members taking part in the 'Future Leaders' program

- IT-LG4: Linking employee goals to JM strategy

9. LG4M1- Number of Balanced Scorecards for Employees

- IT-LG5: Continuous learning and learning from experts

10. LG5M1- Number of creative ideas

- IT-LG6: Optimal use of technology

11. LG6M1- Technical applications readiness indicator for department tasks

12. LG6M2- Automated applications use indicator

Financial perspective objectives and KPIs

- IT-F1: Optimal use of available resources

1. F1M1- Actual expenditure from e-Government budget

2. F1M2- Percentage of actual to projected spending

- IT-F2: Ensure sustainable and diverse sources of income

3. F2M1- The number of public private partnership technical projects.

As can be seen, the JM IT BSC has 38 KPIs in total, with 15 Customer related KPIs, representing 6 different Customer related strategic objectives, 8 Internal Process related KPIs, representing 5 different Internal Process related strategic objectives, 12 Learning and Growth related KPIs, representing 6 different Internal Process related strategic objectives, and 3 Financial related KPIs, representing 2 different Financial related strategic objectives.

As an example, for the KPI C1M1: Percentage of resolved complaints and incidents, Figure 5 demonstrates the value of the KPI over an eight month period. The average value of the KPI indicates that the reading is "yellow" which means the target for the indicator so far was not met. The target value should be an average of $95 \%$ 
throughout the year. So far the overall value is $91 \%$. Each of the KPI scores are evaluated and presented to the IT department heads on a monthly basis in a similar manner through the monthly strategy review. Quantifying the results of performance and presenting them using such graphics help managers work on those objectives which have not been met. They enable managers to have a clearer more focused vision and to work on those initiatives which truly improve performance to achieve strategic objectives effectively.

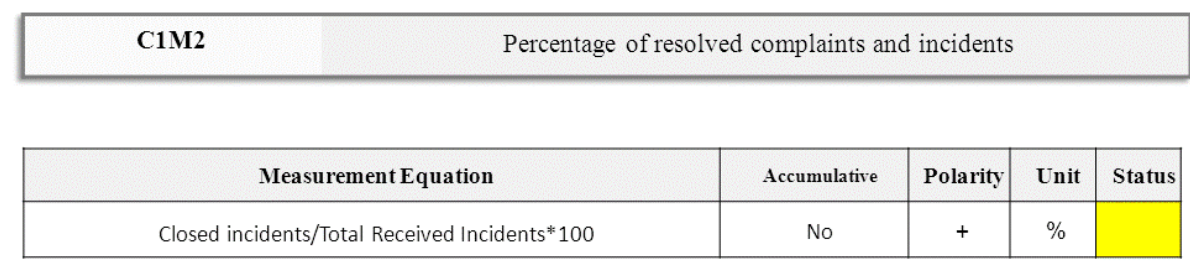

\begin{tabular}{|c|c|c|c|c|c|c|c|c|c|c|c|r|}
\hline Jan & Feb & March & April & May & June & July & Aug & Sep & Oct & Nov & Dec & \\
\hline$\% 91$ & $\begin{array}{c}100 \\
\%\end{array}$ & $\% 95$ & $\% 99$ & $\% 100$ & $\% 97$ & $\% 98$ & $\% 99$ & - & - & - & - & $\begin{array}{r}\text { Current } \\
\text { Value }\end{array}$ \\
\hline$\% 95$ & $\% 95$ & $\% 95$ & $\% 95$ & $\% 95$ & $\% 95$ & $\% 95$ & $\% 95$ & - & - & - & - & Target Value \\
\hline$\% 90$ & $\% 90$ & $\% 90$ & $\% 90$ & $\% 90$ & $\% 90$ & $\% 90$ & $\% 90$ & - & - & - & - & $\begin{array}{r}\text { Warning } \\
\text { Level }\end{array}$ \\
\hline$\% 91$ & $\begin{array}{c}100 \\
\%\end{array}$ & $\% 95$ & $\% 99$ & $\% 100$ & $\% 97$ & $\% 98$ & $\% 99$ & - & - & - & - & $\begin{array}{r}\text { Achievement } \\
\text { Level }\end{array}$ \\
\hline
\end{tabular}

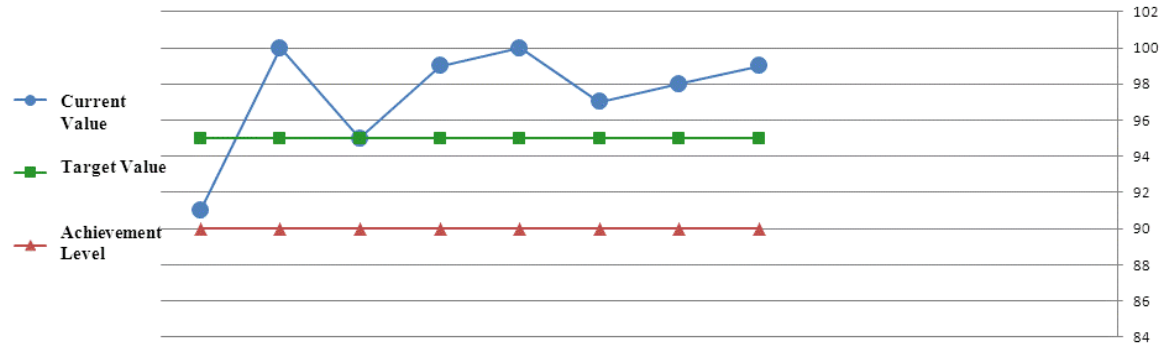

Figure 5. Example: KPI C1M1: Percentage of resolved complaints and incidents (Jeddah Municipality, 2012)

It is also worth noticing that JM IT Department has given different weights for each of the four quadrants. The Customer quadrant (or section of the BSC) was given $50 \%$ of the overall weight of the BSC, indicating the importance of the Customer perspective to the JM IT Department, and following the JM Strategy standard, where departments that are identified as service providers to others departments all use the same weight of $50 \%$ for their Customer perspective, as discussed earlier in this paper. The $\mathrm{L}$ and $\mathrm{G}$ perspective was given $10 \%$ of the overall weight, also based on the JM standard. The remaining 40\% weight was divided between the Financial and Internal Processes quadrants. The Financial quadrant, however, was given the least weight of the four sections, at 5\%. This was justified by the team, as they considered anything less than $5 \%$ will not be of value at all, and so may be totally ignored by managers. Yet, the financial objectives were not among the department main objectives, as the IT Department does not target income generation. The Internal processes objectives were assigned the remaining 35\% of the overall weight, as the second most important perspective. These weights are used by the department when evaluating the overall score of the IT Department performance and how far along they are in successfully implementing the strategy which is targeted to satisfy the strategic objectives stated in the BSC. Once the scores for each KPI are determined, the overall percentage out of $100 \%$ is calculated as follows:

Overall Score $=(C$ Perspective $) / 100+(I P$ Perspective $) / 100+($ L and G Perspective $) / 100+(F$ Perspective $) / 100$

For clarification purposes, assuming that during a strategic review the Customer KPI scores were 45/50, Internal Processes scores were 30/35, L and G scores were 5/10 and Financial scores were 3/5, the overall score for that review for the IT Department can be calculated as: $45+30+5+3=83 \%$; or in other words, the IT Department has achieved $83 \%$ of its strategic objectives for the strategy period. For the set 2009-2014 5-year period at JM, in order for the IT Department to say it has achieved all its strategic objectives, it should reach $100 \%$ or close to it by the end of that period. The strategy monthly review meetings were all KPI scores are reviewed and discussed by the IT managers enable them to see each individual objective and whether or not they are on the correct path and working well towards achieving it, or whether they fell behind. This allows the team to stop, review, think, 
and refocus its efforts constantly, with a higher chance of achieving the correct objectives and placing their efforts in the most strategic valuable ways.

Furthermore, while some KPIs are measured directly, others have their own measurement equation. The JM IT Department is currently working on automating the generation of all measurements, to produce accurate measurements away from evaluator subjectivity. It is important to note that these weights and objectives cover the current strategy period of 2009-2014 and should be reviewed in 2014 again.

The JM IT Department also prepares its annual list of initiatives, each related to a particular strategic objective or to more than one objective. So, in order to address each objective listed in the BSC, the IT Department develops a list of initiatives to carry out targeted to achieve its strategy, as can be seen in Figure 6. An initiative matrix is created mapping out each objective and the initiatives which are identified to successfully realize that objective. The matrix is the roadmap which the IT Department uses to manage its strategy and plan its priorities.

To clarify this, project 3 (Disaster Recovery Center) is used as an example in the Matrix. As shown, The Project is related to IT-C1: Provide highly efficient technology solutions that support business needs and IT-IP1: Provide an effective and secure infrastructure. At the same time, as can be seen from the matrix, IT-IP1 is also affected by other projects, such as Project X, in the matrix. In other words, all projects in the matrix should contribute to $\mathrm{JM}$ achieving at least one of its strategic objectives. If the project does not contribute to any (i.e. no relations can be mapped by the matrix), then that project should not be funded, nor carried out. At the same time, each strategic objective should have sufficient projects that enable JM to achieve the objective by the end of the strategic period 2009-2014.

\begin{tabular}{|c|c|c|c|c|c|c|c|c|c|c|c|}
\hline $\begin{array}{l}\text { Strategic } \\
\text { Objective/ } \\
\text { Project }\end{array}$ & $\begin{array}{l}\text { IT-C1 } \\
\text { Provide highly } \\
\text { efficient } \\
\text { technology } \\
\text { solutions that } \\
\text { support } \\
\text { business needs }\end{array}$ & .. & IT-C6 & $\begin{array}{l}\text { IT-IP1 } \\
\text { Provide an } \\
\text { effective and } \\
\text { secure } \\
\text { infrastructure }\end{array}$ & .. & IT-IP5 & IT-LG1 & .. & IT-LG6 & IT-F1 & IT-F2 \\
\hline $\begin{array}{l}\text { Project } 1 \\
\text { (CRM } \\
\text { System) }\end{array}$ & & & & & & & & & & & \\
\hline $\begin{array}{l}\text { Project } 2 \\
(\ldots)\end{array}$ & & & & & & & & & & & \\
\hline $\begin{array}{l}\text { Project } 3 \\
\text { (Disaster } \\
\text { Recovery } \\
\text { Center) }\end{array}$ & & & & & & & & & & & \\
\hline : & & & & & & & & & & & \\
\hline Project X & & & & & & & & & & & \\
\hline
\end{tabular}

Figure 6. Project and Strategic Objective Matri

(Derived from (Jeddah Municipality, 2012))

JM also uses the matrix to plan its budget. Initiatives with higher weight and impact on the overall strategy get a higher priority for budgeting. Projects with no impact on any of the identified objectives and measures in the strategy do not get funded. These can be identified when they are found not to fit on the project/objective matrix, i.e. they do not relate to any of the IT strategic objectives, meaning they are not strategically important and so should not be funded. Another Action Plan matrix is also used by the department to map out the stages of the department's 5-year action plan, as shown in Figure 7. 


\begin{tabular}{|l|c|c|c|c|c|}
\hline \multicolumn{1}{|c|}{ Project List } & Budget & 2011 & 2012 & 2013 & 2014 \\
\hline Project 1 (e.g. CRM System) & 5000000 & 2000000 & 3000000 & & \\
\hline Project 2 (...) & 1000000 & & & 1000000 & \\
\hline Project 3 (Disaster Recovery Center) & 23000000 & 13000000 & 4000000 & 5000000 & 1000000 \\
\hline$:$ & & $:$ & & & \\
\hline Project X & 3000000 & & 1000000 & & 2000000 \\
\hline Total & $\mathrm{Xx}$ & $\mathrm{X}$ & $\mathrm{X}$ & $\mathrm{X}$ & $\mathrm{X}$ \\
\hline
\end{tabular}

Figure 7. Project/Budget Distribution Matrix used for budget planning

(Derived from (Jeddah Municipality, 2012))

\section{Proposed BSC Model for IT Departments in Government Organizations}

In summary, the JM IT Department uses its customized BSC to manage its strategy implementation as well as to improve its performance and direction to improve overall customer satisfaction. It also uses it for budget planning purposes and performance measurement and reporting. The BSC has become an instrumental tool for the JM IT Department. The JM IT Department over the past three years won several regional IT awards, including Best Regional Strategic Website (2012), Best e-Government in the region (2011), The National Digital Excellence Award (2010), Best national government e-participation initiative (2013) and many others.

This paper proposes that a similar methodology and balanced scorecard construction can be followed by other IT Departments in government organizations, where the IT function is a service provider and not a profit center. Reordering the quadrants and placing the customer perspective at the top of the BSC, with a heavy weight of 50\% of the strategic goals can be used for such organizations. Furthermore, the methodologies used to construct the detailed implementation plan, along with budget planning, are all efforts that can be learned from and used by similar organizations, especially those which are mainly targeted for people service. The two matrices: the Project and Strategic Objectives Matrix and the Project and Budget Planning Matrix are two tools that can be used by other similar organizations while using a BSC to manage a strategy, whether an IT Strategy or otherwise. The tools have been essential in achieving objectives and guiding strategic planning at JM.

\section{Conclusion}

The BSC is a framework for organizations to use to translate their missions and strategies into a comprehensive set of performance measures that enable them to manage their strategies by giving them overviews of how much of their strategies they have achieved, what their issues are, and how they can move towards achieving more of their goals. The BSC was originally introduced to improve corporate performance measurement by balancing lagging metrics of financial performance with nonfinancial metrics that drive future performance, thus extending its use from a performance evaluation tool to a strategy management tool.

This paper described how JM adapted the traditional BSC to match its specific strategic objectives as a nonprofit public service organization, placing its Financial perspective as an input and its Customer perspective measures as the final outcome and the most important of the four perspectives.

The paper later described how the JM IT Department has developed its BSC to be aligned with the main JM $\mathrm{BSC}$, including the new order of its four quadrants. The paper addressed each of the quadrants, its stated strategic objectives, and the measures.

The adaptation of the JM BSC variation can be used as a model for other public service organizations in strategy management and performance evaluation. Furthermore, the JM IT Strategy is managed using the JM IT BSC. It has been used for the past three years and has been a very valuable tool. The IT Department at JM itself has been a model for several governments IT departments in Saudi Arabia and has won regional recognition evident by the 14 prestigious national and regional awards it won over the past four years. The JM IT BSC can thus serve as a model for IT Strategies for similar government organizations which are targeted for public service. The paper, in general, can provide guidance and insight for strategists and IT practitioners on the use of BSC successfully as a framework for performance measurement and strategy management. The paper also proposes two tools that complement the BSC in strategy management in organizations, which are the Project and Strategic Objectives Matrix and the Project and Budget Planning Matrix. These tools help managers and strategists to plan and manage strategies and budgets more efficiently. 
The author hopes that this new alteration of the BSC can help government organizations make better use of BSCs where their main focus should be on the stakeholder perspectives.

\section{References}

Anthoula, K., \& Alexandros, H. (2011). Designing a balanced scorecard for the evaluation of a local authority organization. European Research Studies, 14(2), 65-80.

Banker, R. D., Hsihui, C., \& Pizzini, M. (2011). The judgmental effects of strategy maps in balanced scorecard performance evaluations. International Journal of Accounting Information Systems. http://dx.doi.org/10.1016/j.accinf.2011.08.001

De Geuser, F., Mooraj, S., \& Oyon, D. (2009). Does the balanced scorecard add value? Empirical evidence on its effect on performance. European Accounting Review, 18(1), 93-122. http://dx.doi.org/10.1080/09638180802481698

Gomes, J., Romão, M. \& Caldeira, M. (2013). Linking Benefits to Balanced Scorecard Strategy Map. Advances in Information Systems and Technologies, 357-369. http://dx.doi.org/10.1007/978-3-642-36981-0_34

Jeddah Municipality. (2012). The Jeddah Municipality IT Strategy Document. Jeddah, Saudi Arabia.

Kaplan, R. S. \& Norton, D. P. (1996c). Linking the balanced scorecard to strategy. California Management Review, 39(1), 53-79. http://dx.doi.org/10.2307/41165876

Kaplan, R. S. \& Norton, D. P. (2001b). The Strategy Focused Organization. Harvard Business School Press, Boston, MA.

Kaplan, R. S., \& Norton, D. P. (1992). The balanced scorecard-measures that drive performance. Harvard Business Review, 70(1), 71-79.

Kaplan, R. S., \& Norton, D. P. (1996a). The Balanced Scorecard: Translating Strategy into Action. Harvard Business Press.

Kaplan, R. S., \& Norton, D. P. (1996b). Using the Balanced Scorecard as a Strategic Management System. Harvard business review, 74(1), 75-85.

Kaplan, R. S., \& Norton, D. P. (2000). The strategy-focused organization: How balanced scorecard companies thrive in the new business environment. Harvard Business Press.

Kaplan, R.S. \& Norton, D. P. (2001a). Transforming the Balanced Scorecard from Performance Measurement to Strategic Management: Part I. American Accounting Horizon, March, 15(1), 87-104.

Keyhanifar, N., Mohsen, R. M., \& Shahraki, A. (2012). Evaluating IT performance using combined model of balanced scorecard and fuzzy analytic hierarchy process. Interdisciplinary Journal of Contemporary Research in Business, 3(9), 1267-1277.

Mark, L. F. (2012). The balanced scorecard: 20 years and counting. Strategic Finance, 94(4), 49-53.

Niven, P. (2008). Balanced Scorecard: Step-by-Step for Government and Nonprofit Agencies. Wiley, Hoboken, NJ.

Niven, P. R. (2003). Balanced Scorecard Step by Step: Maximizing Performance and maintaining Results. John Wiley and sons.

Simon, S. J. (2005). Balanced Scorecard: A Tool to Improve IS Department Planning and Evaluation. Journal of Information Technology Case and Application Research, 7(4), 7-29.

Susan, B. A. (2011). Website of the month: Balanced scorecard institute. The CPA Journal, 81(5), 72-73. 